\title{
Firm Attributes Count and Management Accounting Practices in an Emerging Market
}

\author{
Stanley Ogoun*, Sawyerr Ayaundu \\ Department of Accountancy, Faculty of Management Sciences, Niger Delta University, Wilberforce Island, Bayelsa State, Nigeria \\ Email address: \\ stanleyogoun@ndu.edu.ng (S. Ogoun), stanleyogoun@gmail.com (S. Ogoun), ayandue@gmail.com (S. Ayaundu) \\ ${ }^{*}$ Corresponding author
}

\section{To cite this article:}

Stanley Ogoun, Sawyerr Ayaundu. Firm Attributes Count and Management Accounting Practices in an Emerging Market. International Journal of Business and Economics Research. Vol. 9, No. 3, 2020, pp. 94-102. doi: 10.11648/j.ijber.20200903.11

Received: March 9, 2020; Accepted: March 26, 2020; Published: April 17, 2020

\begin{abstract}
The birth of globalization has brought about the introduction of new technologies and means of production which exposes developing countries to greater competition. This has resulted in the alteration of the business environment, thereby changing the dynamics of firm characteristics. In view of the foregoing, this paper examines whether or not attributes count of a firm (FAC) influences the Management Accounting Practices (MAPs) adopted. This effort is hinged on the manufacturing sphere, using primary data sourced through the issuance of structured questionnaires. Firm attributes count was discriminated on the basis of; size, intensity of market competition, grade of accounting staff and technology deployed. A sample size of 80 firms was adopted, with the Spearman correlation coefficient method employed to analyse the data. The empirical outcome of this effort unveils that, all the firm attributes count deployed in this study significantly influence MAPs. Therefore, the study concludes that the type of management accounting tool deployed in any firm, is firm size, intensity of market competition, quality of accounting staff and the level and nature of tech dependent, and that domain differences does tinker with the nature of the effect of these variables. On the basis of the foregoing, it is recommended that smaller firms should deploy outsourcing of management accounting services to augment the lack of quality accounting staff, explore opportunities of alternatives of improved, but cheaper, technology to deploy towards improving the competitiveness, and deploy firm-clustering paradigm to take advantage of combined resource utilisation.
\end{abstract}

Keywords: Firm, Attributes, Management Accounting Practices, Size, Competition, Technology

\section{Introduction}

Globalization is a prime driver of economic activities. With the birth of globalization, the world is now a global village which has increased the level of competition among industries all over the world [28]. These adjustments in business environment have ignited changes in certain firms' characteristics; such as strategy, culture, size and manufacturing technology among others $([11,1,33])$. With the introduction of computerized technologies, an assortment of issues identifying with pricing techniques, cost management and control components are clear, as there are adjustments in management accounting systems, structures, thinking, and practices [12]. These changes may influence the decision of management accounting practice (MAP) in an organisation and may likewise bring about the requirement for the firm to rethink its current organisational plan and procedures so as to align with the evolving environment [32][33]. These changes in business environments have been discriminated as reasons why, change in management accounting practices is unavoidable ([26, 25, 44]).

Management Accounting Practices (MAP) incorporate cost practices, planning, and data for dynamic, strategic investigation and performance examination, utilising management accounting strategies [21]. The traditional management accounting practices such as; standard costing, marginal costing and assimilation (absorption) costing have been censured for being too frail, to even think about coping with the dynamic environment of the 21 st century business, since they are subservient to money related accounting and thus delivers data that is excessively amassed and too contorted to be in any way applicable for managerial planning, control and efficient decision support ([26, 25, 45, 44]). New management accounting practices, which are more 
advanced than the traditional methods have been developed and proposed for specialists' $([13,4])$. The new practices incorporate movement-based (activity-based) costing, balanced scorecard, target costing, life cycle costing, total quality management, in the nick of time, throughput accounting and backflush accounting, among a few others ([6, 45, 32]).

In any case, despite overwhelming reactions to traditional procedures and a great deal of advantages were ascribed to the cutting-edge practices by numerous researchers. The extant literature shows that the traditional methods are as yet being utilised in advanced, emerging and developing economies, while the new systems have not been completely grasped by numerous firms $([6,4,10,39])$. The field of MAPs have been unmistakably outlined in the established literature. An exploratory audit of any standard Management Accounting content will turn up an array of MA apparatuses and their applications. Subsequently, there is no controversy with respect to substance and accessible to MA methodologies. Whereas, the mode of application varies from one context to another. By the dynamic idea of MA instruments, portrayed by adaptability in applications, organisations are furnished with plentiful influence to choose suitable devices that best suits their peculiarity, instead of universalities. Moreover, the literature additionally archives reasonable properties', ventures, as well as, firms by augmentation. This stipulation, empowers the arrangement of enterprises and by extension firms on obviously defined benchmarking format.

Debates have been advanced by [40] that a key policy issue that the Nigerian government should confront, is how to comprehend and address the factors that will upgrade the efficiencies of companies, which will thus increase their intensity. [9] observed that the appropriation of the combination of reasonable management strategies, with reasonable technology and different assets, can take care of the issue of low productivity. Besides, management accounting has been proposed as an important management tool that can help guarantee productivity in the utilisation of companies' assets (IFAC, 1998). Notwithstanding, earlier studies have distinguished the shortage of concentrates on management accounting systems in developing nations, especially among non-recorded (informal) small and medium enterprises $([21,32,33,30,20])$. Based on this, the study interrogates the connection between firm attributes index and utilisation of management accounting methodologies in Nigeria, anchored on the manufacturing sphere.

\section{The Literature}

\subsection{Firm Attributes Count and Conceptual Framework}

Internal management purpose is the reason for the practice of management accounting [35]. [36] posits that the essence of management accounting is for data storage that will be used for proper business analysis in an organisation. Management accounting practices encourage successful choices and assist organisations in advancing planned practices [8]. Successful choices are made with management accounting, since records of past events are kept [17].

It is better for larger organisations to have proper management accounting system that will help manage cost of operations [3]. Smaller companies are likely to embrace traditional MAPs rather than present day MAPs [19]. Be that as it may, as a firm grows, managers need to deal with more noteworthy measures of amounts and data, as bigger entities have more measures of assets and are in a prevailing situation to control their environment with the utilisation of MAPs [5]. Besides, in nations such as Estonia, MAPs became significant when the size of manufacturing companies developed, requiring more subtleties to measure the performance of their companies concerning the business locally and customer offerings [19]. Organisation size, as such, may affect MAPs, as enormous organisations will in general embrace MAPs contrasted with Micro, Small and Medium Enterprises (MSMEs). The likelihood of 'may' lies in the very substance and truth, that the traditional model of firm size (based on enormous physical asset holding) appears to be eroding by the current smart firm models of high technology-based typologies, as a great many of the main and profitable firms of today, don't boast of huge physical-asset holding.

The business of today is very competitive and the role played by management accounting in having competitive advantage can never be underestimated. With management accounting, the organisation can plan effectively and manage its competition [3]. Be that as it may, one fascinating element of tech-driven disturbances is the changing of the traditional fixed asset-based type of business holding. Shrewd firms are developing, relying on technology to gain upper hand over the traditional firms. The established literature reports this, as indicated by the worldwide positioning of the world's richest men, who in general, are proprietors of tech-content driven firms.

Besides, the financial information domain has increased in complexity, owing to the rapid change in transactions mainframe. Complex patterns of transacting business on eplatforms have made financial operations to take-on behavioural dispositions that require smart accounting personnel to deal. Thus, accounting staff with the needed qualifications and expertise will play a great role in managing the books of a company. Thus, proper management accounting can be achieved with qualified accountants [14]).

Furthermore, technology, as a key factor in every society has a way of affecting the management of accounting and production system of a company. It affects the accounting system, especially manufacturing companies [19]. As such, complex manufacturing procedures escalate the need for advanced management accounting methodologies, invariably accentuating MAPs into becoming increasingly mind boggling and advanced [19]. Companies utilising present day technology in its production activities may influence MAPs. Production technology is often constrained in MSMEs, as bigger firms are more amenable to technology to assist their 
production processes contrasted with MSMEs. Most production patterns of activities have changed in the $21 \mathrm{st}$ century, due to evolving technology. It has been discovered that bigger firms change with the evolving technology, but smaller firms are static when it comes to technological changes [2]. The performance of big or small firms is dependent on the technological capacity it has. Bigger firms with new technology will do better than firms without the latest technology.

From several literature, it has been found out that management accounting is influenced greatly by organization size, intensity of market competition, level of qualification of accounting staff and propelled production technology, Additionally, given the changing conduct of these variables, modified from their traditional appearance shapes by techdisturbances, it is basic to question if the determinant result of MAPs in an emerging economy would in any case be the equivalent. What's more, in-nation (Nigerian) based studies, exploring the impact of these four factors on MAPs are rare, subsequently the need to address this gap.

Extant literatures have distinctive significance for firm characteristics which has likewise influenced the scientific system of this idea. Authors such as [42] define such characteristics to infer qualities which are explicit variables that contribute towards the progressions on firm value.

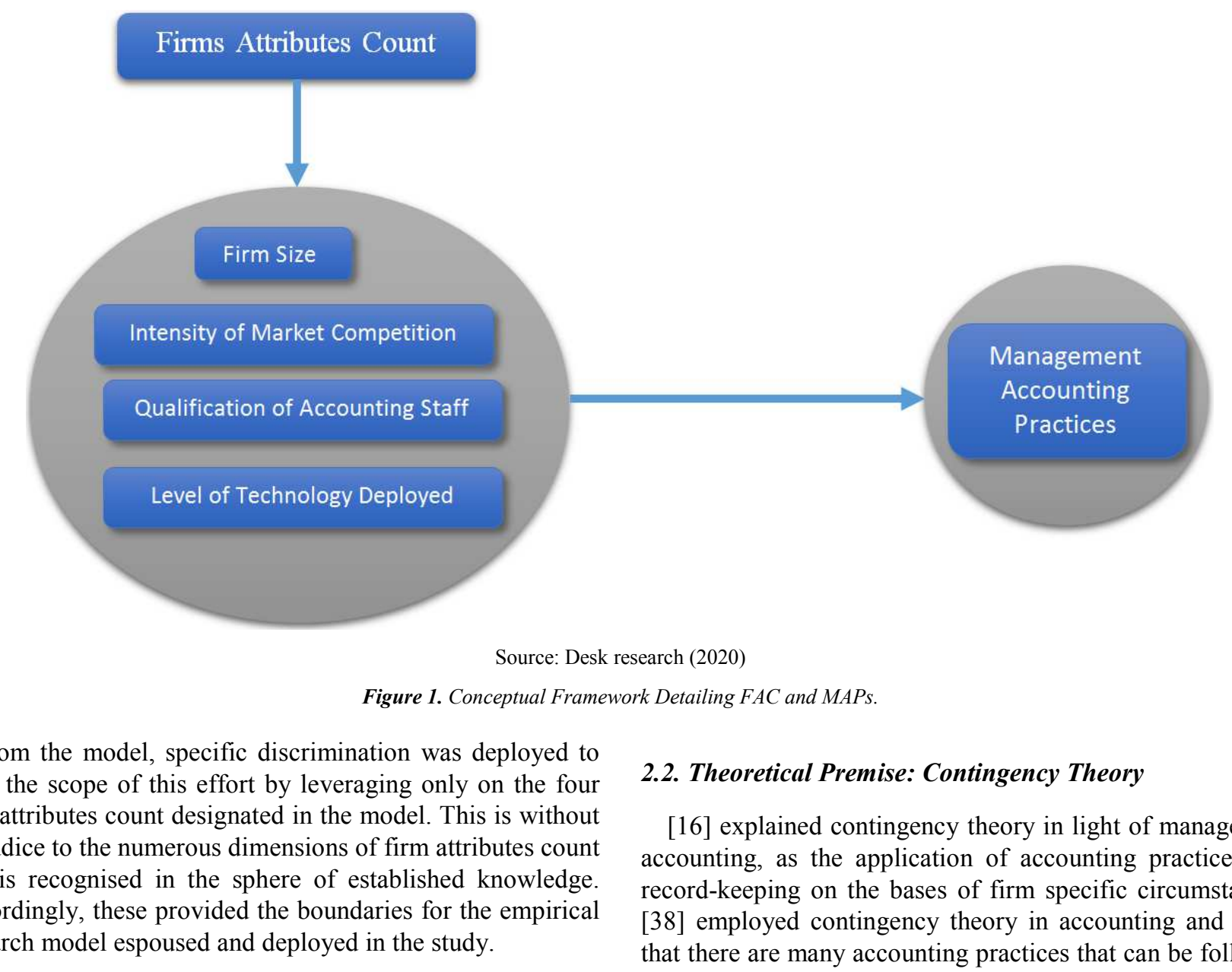

Figure 1. Conceptual Framework Detailing FAC and MAPS.

From the model, specific discrimination was deployed to limit the scope of this effort by leveraging only on the four firm attributes count designated in the model. This is without prejudice to the numerous dimensions of firm attributes count that is recognised in the sphere of established knowledge. Accordingly, these provided the boundaries for the empirical research model espoused and deployed in the study.
Company qualities are isolated into firm performance characteristics and firm structural characteristics. The firm performance trademark incorporates firm growth and profitability, while firm structural characteristics incorporate firm size, firm influence, firm age and capital consumption or management proficiency. It is likewise examined uniquely in contrast to the point of view of MSMEs, in which characteristics allude to the inception of the enterprise, period of time in activity, size of enterprise, and capital sources, which assume significant role on business achievement [23]. [18] assert that firm's assets and targets condensed as firm characteristics, influence performance of organizations. The characteristics recognized by these studies are additionally tallied into: structure, market and capital-related variables. Structure-related variables incorporate firm size, possession and firm age. Market-related variables; incorporate industry type, environmental vulnerability and market environment. Capital-related variables involve liquidity and capital intensity. For [37], the characteristics of firms, such as its age and size are drivers or impetus for performance.

Gleaned from the literature is the anchoring of the idea that firm attributes index is an overall driver of both resource and strategy deployment, leading to goal's attainment. Hence, the conceptualized framework for the current this research effort as encapsulated below:

\subsection{Theoretical Premise: Contingency Theory}

[16] explained contingency theory in light of management accounting, as the application of accounting practices and record-keeping on the bases of firm specific circumstances. [38] employed contingency theory in accounting and states that there are many accounting practices that can be followed by an organisation and none of these practices is peculiar to 
any organisation. What's more, [26] agrees that, contingency theory is established on the rule that, there is no commonly appropriate management accounting system, which applies similarly to all organisations, in all conditions. Of essence, organisations should adopt its own suitable accounting practice. Therefore, this research was premised on the contingency theory, which leverages on firm's circumstances in strategy and methodologies choices.

\subsection{Hypotheses Development}

\section{i. Firm Size}

Earlier investigations have been attempted for the most part in the developed world, on industry and firm types' bearing on MAPs. For example, organisation size is seen as the quantity of workers in the entity. Also, organisation size can likewise be indexed by the set-up capital of the organisation [43]. In this regard, [2] examined 110 Malaysian entities in the manufacturing realm, and uncovered that entity magnitude has a significant impact on MAPs in business tasks, as bigger firms have more resource advantage to encourage MAPs. Additionally, the study deposed that bigger firms required increasingly complex MAPs contrasted with MSMEs. Another study by [24] addressed size as a precursor of MAPs in Egyptian manufacturing firms. The study indicated that size influences typologies of MA tools deployed. Additionally, a lion share of the manufacturing firms in Egypt prefer traditional MAPs, as traditional MAPs are straightforward and are easier to utilise. A further exploration by [34] looking at MAPs in media transmission companies in Ghana, discovered that, the degree of the utilisation and reasons for reception of MAPs in Ghana relied upon the size of the firm.

Size often depicts resource levels. In this manner, greater firms are often invested with higher resource capacity than littler firms. Premised on size, larger firms are very likely to be better positioned to deploy resources to meet MA expectations. Be that as it may, given the changing attitude of what firm size was, as traditionally physical asset holding designated (modified from its traditional appearance structure by techdisturbances), it is inevitable to examine if the determinant result of MAPs in an emerging market would at present still remain firm-size driven? On this basis we hypothesize that:

$\mathrm{H}_{01}$ : There is no significant relationship between organization size and management accounting practices in Manufacturing firms, in an emerging market domain.

ii. Intensity of Competition

Existing literatures distinguished intensity of market competition, as one of the determinants of MAPS. Power of market competition is characterized as one corporate entity competing with one another in a bid to have greater market share [15]. The intensity of market competition is an external factor of competition and managers need to craft new and efficient costing frameworks, to fight in a fierce market. [29] related market competition to MAPs. They deposed that MAPs requirements are occasioned by the multi-faceted nature of the business environment, and that MAPs help entities to choose the benefits realised in each production system. In addition, [31] study on MAPs in South Africa found that, MAPs change in view of the unpredictability of the market competition encountered by organisations.

Also, [19] analysed the effect of the intensity of market competition on MAPs of assembling organisations in Estonia. The disclosure of the investigation anchors the existence of a significant connection between intensity of market competition and MAPs, as the external environment angle affected the possibility of the sufficiency of the ordinary the traditional framework. Along the same line, [43] interrogated the effect of business environment on MAPs of assembling organisations in Malaysia. The output of the study indicated a positive and significant connect between external business environments with MAPs. Moreover, the study found out that organisations' using MAPs in their internal business operations impacted the performance of such organisations.

We underscore the previous settled justification that, expanding high ground in numerous business spaces, is never again dependent on conventional wellsprings of prior methodologies. Technology imbuement and pace of improvement are progressing new sorts of business intrigues and frameworks, that impact on resource and costs sharing designs (for instance blockchain technology, business packs). The foregoing inevitably underscores the essence of market space on resource deployment in general. Given this premise, does this narrative apply to firms in contemporary developing markets? Hence:

$\mathrm{H}_{02}$ : There is no significant relationship between intensity of market competition and management accounting practices in Manufacturing firms, in an emerging market domain.

iii. Qualification of Accounting Staff

The qualification of a staff has a great role in management accounting. A qualified accountant will know what standards to apply in preparing the various book of accounts and this will help create transparency that will increase the confidence and performance of the company. [1] examined the relationship the level of qualification of accounting staff bears on MAPs in United Kingdom (UK). The outcomes showed that the level of qualification of accounting staff does influence the modernity of management accounting methodologies in the organisation.

Also, [19] investigated the influence of qualification of accounting staff and management accounting. The evidence supports that staff qualification has significant influence on management accounting practice. Additionally, the authors noticed that, there are a ton of accounting staff that didn't have legitimate information on efficient ways of utilising accounting data. In addition, [2] did a critical analysis on the impact of management accounting on the accomplishment of SMEs in Malaysia. The result of the investigation underscores management accounting as having major impact on SMEs.

The United Nations Development Programme (UNDP) has found out that a lot of attention is not given to human capital advancement in Nigeria (see UNDP Report on HDI-2018) and this has really affected the quality of access to education in Nigeria. In light of this, the hypothesis below is drawn;

$\mathrm{H}_{03}$ : There is no significant relationship between level of qualification of accounting staff and management accounting 
practices in manufacturing firms, in an emerging market domain. iv. Level of Technology deployed

The performance of manufacturing firms can be improved with advance production technology [2]. [29] investigated how advanced production technology affects management accounting practices. It was uncovered that advanced production technology has enormous impact on management account practice.

The use of advance technological practice makes an organisation to be a market leader. [1] explored the relationship of advanced production technology (APT) and MAPs based on the level of modernity. The output of the study indicated that the distinction in the management accounting refinement are significantly clarified by production technology [2] in his investigation on how advanced production technology affects management accounting practices, unravelled that APT has notable impact on MAPs.

We repeat the earlier settled rationale that, the pace of techdisturbances is very disturbing and massive built up manufacturing infrastructure, may force rigidities that may foreclose easy of new tech-selections and deployment. With advances in technology, specialists are attempting to recognize a superior association between technology speculation and firm's performances by methods for examination ([48, 47, 41]).

Consequently, the need to investigate if technology is as yet a determinant of MAPs in developing markets. The previous literature anchors the premises for the hypothesis proposed here:

$\mathrm{H}_{04}$ : There is no significant relationship between advanced production technology deployment and management accounting practices in Manufacturing firms, in an emerging market domain.

$$
M A P=\beta_{0}+\beta_{1} \text { ORGSIZE }+\beta_{2} I N M K T C O M+\beta_{3} L E Q U A L A C C+\beta_{4} A D V P R O T E C H+\mu
$$

Where; MAPS is MAPS; ORGSIZE is organizational size; INMKTCOM means intensity of market-competition;

\section{Methodology}

This study adopts the survey research design. The population of this study is manufacturing firms in Rivers State and a sample size of 80 was gotten following the use of Yaro-Yamane sampling technique. The data used for this study were mainly primary data. All the primary data collection through questionnaires was accomplished via personal contacts with the heads of the various accounting units, accounts managers and senior personnel of accounts departments of the firms. The questionnaire was structured to reflect the Likert scale 5-point scale of Strongly Disagree (1), Disagree (2), Neutral (3), Agree (4) and Strongly Agree (5).

The data sourced using the structured questionnaire was analysed using the Spearman Rank Correlation Coefficient Method. Following the global usage of application software in the analysis of data, the Statistical Package for Social Sciences (SPSS) was used for the study.

The model adopted is as presented mathematical in the formula as follows:

$$
\rho=\frac{\sum_{i}(X i-\bar{x})(Y i-\bar{y})}{\sqrt{\sum_{i}(X i-\bar{x})^{2} \sum_{i}(Y i-\bar{y})^{2}}}
$$

Where $\mathrm{i}$ is paired score. Generally, the Spearman rank order correlation test formula is expressed as follows:

$$
\rho=1-\frac{6 \sum d_{i}^{2}}{n\left(n^{2}-1\right)}
$$

Where; $d_{i}$ is difference in paired ranks and $n$ is number of cases. For the purpose of empirical modelling the association is expressed as follows:

\begin{tabular}{|c|c|c|c|c|c|}
\hline & MAPS & ORGSIZE & INMKTCOM & LEQUALACC & ADVPROTECH \\
\hline Mean & 704.7476 & 137.6694 & 23.38215 & 2282.265 & 254.3904 \\
\hline Median & 771.2003 & 132.8237 & 23.53819 & 1853.316 & 260.7259 \\
\hline Maximum & 1152.796 & 158.5526 & 24.11434 & 4368.641 & 406.3465 \\
\hline Std. Dev. & 298.6843 & 16.18758 & 0.432804 & 1389.616 & 121.7023 \\
\hline Skewness & -0.104709 & 0.005465 & -0.102809 & 0.318539 & -0.576144 \\
\hline Kurtosis & 1.718140 & 1.550092 & 1.840182 & 1.484614 & 2.375806 \\
\hline Prob. & 0.611373 & 0.541622 & 0.667193 & 0.454680 & 0.605983 \\
\hline Sum & 9866.466 & 1927.372 & 327.3501 & 31951.71 & 3561.466 \\
\hline Sum Sq. Dev. & 1159760. & 3406.492 & 2.435150 & 25103435 & 192548.8 \\
\hline
\end{tabular}

$L E Q U A L A C C$ is level of qualification of accounting staff and $A D V P R O T E C H$ is advanced production technology.

Table 1. Descriptive statistics regression output.

Source: Computational output

\section{Data Analysis and Outputs}

Presented in table 1 is the analytical output associated with descriptive statistics. On the table above, the mean of MAPS is 704.7476 with a standard deviation of 298.6843 , which shows tendency of higher dispersion from the mean. It is also adversely skewed, given a coefficient of -0.104709 . Intensity of market- 
a premise for the correlation analysis to determine strength of association among criterion variables and the reliant variable. The results of the correlation test are displayed below for each of the operationalized dimensions of firm characteristics:
$\mathrm{H}_{01}$ : There is no significant relationship between organization size and management accounting practices in Manufacturing firms, in an emerging market domain.

Table 2. Correlation analysis showing the association among organisation size and MAPS.

\begin{tabular}{|c|c|c|c|c|}
\hline & & & Organization Size & MAPS \\
\hline \multirow{5}{*}{ Spearman's rho } & \multirow{3}{*}{ Organization Size } & Correlation Coefficient & 1.000 & $.725^{* *}$ \\
\hline & & Sig. (2-tailed) & . & .000 \\
\hline & & $\mathrm{N}$ & 78 & 78 \\
\hline & \multirow{2}{*}{$\begin{array}{l}\text { Management } \\
\text { Accounting Practices }\end{array}$} & Sig. (2-tailed) & .000 & . \\
\hline & & $\mathrm{N}$ & 78 & 78 \\
\hline
\end{tabular}

**. Correlation is substantial at the 0.01 level (2-tailed).

Source: Own computation using SPSS 21

As evidenced from the result above, a positive association exists among organisation size and MAPS as made known by the Spearman's rank coefficient computed to be 0.725 . The discovered association was unravelled to be substantial following the prob. figure of 0.000 which is less than the 0.05 level. Thus, it implies that the size of the organization is a determinant of the kind of MAPS adopted. This may not be unconnected with their resource endowment or capacity. In general terms, it is a truism that the size of the firm is a major determinant of both the capacity of the firm and the nature of its procedures. This result using the study's data base tallies with results of prior studies done in other climes by $([43,2]$ [34]). This implies that there is domain differentiation in the adoption of MAPS, given firm size as a denominator.

$\mathrm{H}_{02}$ : There is no significant relationship between intensity of market competition and management accounting practices in Manufacturing firms, in an emerging market domain.

Table 3. Correlation analysis showing the association between market-competition and MAPS.

\begin{tabular}{lllll}
\hline & & Market Competition & Management Accounting Practices & $.735^{* *}$ \\
\hline & \multirow{4}{*}{ Market-competition } & Correlation Coefficient & 1.000 & .000 \\
Spearman's rho & & Sig. (2-tailed) &. & 78 \\
& & $\mathrm{~N}$ & 78 & .7 .000 \\
& MAPS & Correlation Coefficient & $.735^{* *}$ &. \\
& & Sig. (2-tailed) & .000 & 78 \\
\hline
\end{tabular}

**. Correlation is substantial at the 0.01 level (2-tailed).

Source: Own computation using SPSS 21

Table 3 As discovered by the result above, a positive association was observed to exists among marketcompetition and MAPS. Further examination unravelled that, the positive association among market-competition and MAPS is substantial as the prob. figure of 0.000 is below the 5 percent (0.05) level of significance. This shows that the interior and exterior competitive factors affecting companies have an impact on the method of MAPS adopted. This implies that interior factors such as technology if improved can create a favourable position for better competitive advantage in a firm's industry of operation. On other hand exterior factors like business and accounting would greatly affect the level of sophisticated MAPS applied by the firm.

$\mathrm{H}_{03}$ : There is no significant relationship between level of qualification of accounting staff and management accounting practices in manufacturing firms, in an emerging market domain.

Table 4. Correlation analysis showing the extent of link between qualification of accounting staff and MAPS.

\begin{tabular}{|c|c|c|c|c|}
\hline & & & Level Accounting Staff & MAPS \\
\hline \multirow{6}{*}{ Spearman's rho } & \multirow{3}{*}{ Level Accounting Staff } & Correlation Coefficient & 1.000 & $.648^{* *}$ \\
\hline & & Sig. (2-tailed) & . & .000 \\
\hline & & $\mathrm{N}$ & 78 & 78 \\
\hline & \multirow{3}{*}{$\begin{array}{l}\text { Management } \\
\text { Accounting Practices }\end{array}$} & Correlation Coefficient & $.648^{* *}$ & 1.000 \\
\hline & & Sig. (2-tailed) & .000 & . \\
\hline & & $\mathrm{N}$ & 78 & 78 \\
\hline
\end{tabular}

**. Correlation is substantial at the 0.01 level (2-tailed).

Source: Own computation using SPSS 21

Level of accounting staff and MAPs correlate at .648, when the p-figure is $0.000<0.05$. This signify a strong correlation among level of accounting staff and MAPs. The high level of correlation among the two variables shows that the more complicated the manufacturing stages, the more sophisticated the MAPs applied. Hence the need for properly trained and adequately qualified accounting staff to run the MAPs to be applied. Therefore, big sized firmed whose 
manufacturing stages are highly automated are compelled to recruit qualified and skilled accounting staff.

$\mathrm{H}_{04}$ : There is no significant relationship between advanced production technology deployment and management accounting practices in Manufacturing firms, in an emerging market domain.

Table 5. Correlation analysis showing the association between advanced production technology and MAPS.

\begin{tabular}{|c|c|c|c|c|}
\hline & & & Advanced Production Technology & MAPS \\
\hline \multirow{6}{*}{ Spearman's rho } & \multirow{3}{*}{ Advanced Production Technology } & Correlation Coefficient & 1.000 & $.617^{* *}$ \\
\hline & & Sig. (2-tailed) & . & .000 \\
\hline & & $\mathrm{N}$ & 78 & 78 \\
\hline & \multirow{3}{*}{ MAPS } & Correlation Coefficient & $.617^{* *}$ & 1.000 \\
\hline & & Sig. (2-tailed) & .000 & . \\
\hline & & $\mathrm{N}$ & 78 & 78 \\
\hline
\end{tabular}

**. Correlation is substantial at the 0.01 level (2-tailed).

Source: Own computation using SPSS 21

Table 5 above reports the correlation analysis advanced production technology and MAPs. From the empirical result above, advanced production technology and MAPs correlate at .617 as the prob. figure of .000 is less than 0.05 level of significance. This suggests that there is a strong positive association between advanced production technology and MAPs in manufacturing firms in Rivers State. The figures depict a need for more sophisticated MAPs where production technology is more complicated and automated. Hence, larger firms rely on highly automated systems due to their large production capacity amongst other factors and to ensure the smooth operation of this system, more modern MAPs are usually applied.

\section{Conclusion, Implications and Recommendations}

The study was espoused to look at the degree to which MAPs applied in a firm are discriminated by the firm's attributes count. The study discriminated four elements of the firm's attributes count. Specifically; organization size, intensity of market-competition, level of qualification of accounting staff and advanced production technology, to unravel if the output in an emerging market domain, would counter or confirm extant research outputs in other climes. The quintessence is to comprehend if economic status of firm location, stimulates differential outcome in the interplay of these discriminated variables of the study. The exploration discoveries uncovered that MAPS are influenced by organisation size, intensity of market-competition in the industry, level of qualification of accounting staff and advanced production technology in the firm, regardless of the market sphere of the firm. Therefore, it is inferred that FAC, influences MAPs, regardless of market domain considerations.

The ramifications of size on MAPs is very informational. It unmistakably shows that the old index of firm size predominance in specific instances, despite advances in technology (emergence of smart firms), applies here as well. The outcome of size influence is very instructive, as it tends to negative the idea of rigidity for bigger firms, thus limiting easy adaptability of newer methodologies. This is given that technological disturbances and the speed of technology change in certain businesses requires some level of flexibility. In this way, it was assumed that smaller firms would leverage on their flexibility to adopt new methodologies, yet the result proposes that the bigger firms are better ready to deploy new MAPs. This observation isn't detached from the resource endowed capacity of bigger firms. However, this outcome which is intra-industry firm based, might probably not pan out, where inter-industry basis is operationalised. It suggests that the bigger the organisation, the more complex the MAPs embraced. Along this line, the ramifications of such association, taking everything into account, is that growing organisational size, means rising management accounting necessities and by extension practices.

Essentially, intensity of market-competition, was seen to exert substantial influence on MAPs. This is very smart, as the intensity of competition in a market drives firms towards advancing and conveying strategic choices to secure competitive edge. The spot of MA in enabling relevant data gathering, aggregating cost-effective alternatives, market opportunity-taking, and so forth is very much recorded in the extant literature. This plainly hints that firm performance and continuity, in a market denominated by serious competition is hinged on embracing best practices to acquire upper hand. Likewise, given the idea of refinement, associated with more recent tools of MA, it assumes that well qualified and talented accounting faculty can use them better. Hence, the result of the outcome simply reaffirms what is known. Be that as it may, given the new worldview of brilliant systems and firms, firms without capacity to maintain such talented work force as staff could explore the widow of appropriating outsourcing. This is because the reigning business model, flourishes under the format of a lean organisation structure, with insubstantial staff, yet exploiting service providers business models to leverage on their shortfalls.

The deposition of manufacturing technology determination of MAPs is smart. Right now, transformation, tech-driven tasks trademark the whole global business scene, with disturbances in an unheard-of scale. Strikingly, technological arrangement influences the procedure of choice help data. Consequently, higher technology arrangement suggests more noteworthy necessity for advice, following and catching reliance on advanced data tools and sets. This certainly 
implies that as a firm increases its technology-base, its requirements for advanced accounting systems would increase correspondingly, as most advanced systems are not amenable to traditional MA tools.

Going by the outcome, it is prescribed that smaller firms should deploy outsourcing of MA services to augment the lack of quality accounting staff, explore opportunities of alternatives of improved, but cheaper, technology to deploy towards improving competitiveness, and deploy firmclustering paradigm to take advantage of combined resource utilisation.

\section{References}

[1] Abdel-Kader, M., \& Luther, R. (2008). The impact of firm characteristics on management accounting practices: A UKbased empirical analysis. British Accounting Review, 40, 2-27.

[2] Ahmad, K (2012). Factors explaining the extent of use of MAPs in Malaysian medium firms. Asian Entrepreneurship Conference 2012.

[3] Ahmad, K. (2014). The adoption of MAPs in Malaysian small and medium-sized enterprise. Asian Social Science, 10 (2), 236-249.

[4] Ajibolade, S. O. (2013). Drivers of Choice of Management Accounting System Designs in Nigerian Manufacturing Companies. International Journal of Business and Social Research (IJBSR), 3, 45-57.

[5] Albu, N., \& Albu, C. (2012). Factors associated with the adoption and use of management accounting techniques in developing countries: The case of Romania. Journal of International Financial Management \& Accounting, 23 (3), 245-276.

[6] Askarany, D., \& Smith, M. (2008). Diffusion of innovation and business size: A longitudinal study of PACIA. Managerial Auditing Journal, 23, 900-916.

[7] Askarany, D., Smith, M., \& Yazdifar, H. (2007). Technological Innovation, Activity Based Costing and Satisfaction. Journal of Accounting - Business \&Management, 14, 53-63.

[8] Axelsson, B.; Laage-hellman, J. \& Nilsson, U. (2002). Modern management accounting for modern purchasing. European Journal of Purchasing \& Supply Management, 8 (1), 53-62.

[9] Ayodele, A. S., \& Falokun, G. (2003). The Nigerian Economy: Structure and Pattern of Development. Ibadan: Jodab Publishers.

[10] Badem, A. C., Ergin, E., \& Dury, C. (2013). Is Standard Costing Still Used? Evidence from Turkish Automotive Industry. International Business Research, 6 (7).

[11] Baines, A., \& Langfield-Smith, K. (2003). Antecedents to management accounting change: A structural equation approach. Accounting, Organizations and Society, 28 (7-8), 675-698.

[12] Bhimani, A. (2003). Management Accounting in the Digital Economy. Oxford University Press.
[13] Bhimani, A., \& Bromwich, M. (2010). Management Accounting: Prospect and Retrospect. Great Britan: ELSEVIER.

[14] Brown, A., Booth, P., \& Giacobbe, F. (2004). Technological and organizational influences on the adoption of activitybased costing in Australia. Accounting and Finance, 44 (3), 329-356.

[15] Cadez, S., \& Guilding, C. (2008). An exploratory investigation of an integrated contingency model of strategic management accounting. Accounting, Organization and Society, 33, 836-863.

[16] Donaldson, L. (2001). The contingency theory of organizations. Thousand Oaks, CA: Sage Publications.

[17] Gichaaga, P. M. (2014). Effects of MAP on financial performance of manufacturing companies in Kenya. Master of Science in Finance Dissertation, School of Business, University of Nairobi.

[18] Golan, E.; Krissoff, B.; Kuchler, F. F.; Nelson, K.; Price, G.; \& Kelvin L. (2003). Traceability in the US food supply chain: dead end or superhighway? In Choices Vol. 2nd quarter.

[19] Haldma, T., \& Laats, K. (2002). Influencing contingencies on MAP in Estonian manufacturing companies. University of Tartu - Economics and Business Administration Working Paper No. 13.

[20] Hopper, T., \& Bui, B. (2016). Has Management Accounting Research been critical? Management Accounting Research, 31

[21] Hopper, T., Tsamenyi, M., Uddin, S., \& Wickramasinghe, D. (2009). Management Accounting in Less Developed Countries: What is Known and Needs Knowing Management accounting in less developed countries: what is known and needs knowing. Accounting, Auditing \& Accountability Journal, 22 (3), 469-514.

[22] Horngren, C. T., Datar, S., Foster, G., Rajan, M., \& Ittner, C. (2009). Cost Accounting: A Managerial Emphasis (13th ed.). New Jersey.: Prentice Hall.

[23] Islam, M. A., Khan, M. A., Obaidullah, A. Z. M., \& Alam, M. S. (2011). Effect of entrepreneur and firm characteristics on the business success of small and medium enterprises (SMEs) in Bangladesh. International Journal of Business and Management, 6 (3), 289.

[24] Ismail, T. H., \& Mahmoud, C. (2012). The influence of Organizational and environmental Factors in Cost Systems Design in Egypt. British Journal of Economics, Finance and Management Sciences, Vol. 4 (2), 31-51.

[25] Jhonson, H. T., \& Kaplan, R. S. (1987). Relevance lost: The rise and fall of management accounting. Boston: Harvard Business School Press.

[26] Kaplan, R. S. (1984). The Evolution of Management Accounting. Accounting Review, 59 (3), 390-418.

[27] Kariuki, S. N \& Kamau, C. G. (2016). Organizational contingencies influencing th adoption of strategic MAP among manufacturing firms in Kenya. International Journal of Advanced Research in Management and Social Sciences, 5 (4), 167-182.

[28] Kassim, M. Y., Md-Mansur, K., \& Idris, S. (2003). Globalization and its impact on Malaysia economy. Reinventing Sabah: Global Challenges and Policy Responses, 95-111. 
[29] Leite, A. A, Fernandes, P. O., \& Leite, J. M. (2015). Contingent factors that influence the use of MAP in the Portuguese textile and clothing sector. The International Journal of Management Science and Information Technology. Special Issue: Spanish-Portuguese Scientific Management Conference, (59-77).

[30] López, O. L., \& Hiebl, M. R. W. (2015). Management Accounting in Small and Medium Sized Enterprises: Current Knowledge and Avenues for Further Research. Journal of Management Accounting Research, 27 (1), 81-119.

[31] Luther, R. G., \& Longden, S. (2001). Management accounting in companies adapting to structural change and volatility in transition economies: A South African study. Management Accounting Research, 12, 299-320.

[32] Mat, T. Z. T. (2010). Management Accounting and Organizational Change: Impact of Alignment of Management Accounting Systems, Structure and Strategy on Performance. Edith Cowan University, Perth Western Australia.

[33] Mat, T. Z. T., \& Smith, M. (2014). The Impact of Changes in Environment and AMT on MAP and Organizational Strategy, Structure and Performance. Journal of Applied Management Accounting Research, 12 (1), 55-82.

[34] Mbawuni, J., \& Anertey, A. (2014). Exploring MAP in emerging telecommunication market in Ghana. Accounting and Finance Research, 3 (4), 71-85.

[35] Ndwiga, N. M. (2011). The Role of Management Accounting in Creating and Sustaining Competitive Advantage. A Case Study of Equity Bank, Kenya. Master of Commerce in accounting dissertation. University of South Africa. Pretoria.

[36] Nuhu, N. A.; Baird, K. \& Appuhami, R. (2016). The Association between the Use of MAP with Organizational Change and Organizational Performance. In Marc J.; Epstein, Mary \& Malina, A. ed. Advances in Management Accounting (Advances in Management Accounting, Volume 26, Emerald Group Publishing Limited, 67-98.

[37] O'Sullivan, D., Abela, A. V. \& Hutchinson, M. (2009). Marketing performance measurement and firm performance. European Journal of Marketing, 43 (5/6): 843-862.
[38] Otley, D. (1980). The contingency theory of management accounting research: achievement and prognosis. Accounting, Organizations and Society, 5 (4), 413-428.

[39] Oyerogba, O. E. (2015). The Use of Voluntary Disclosure in Determining the Quality of Financial Statements: Evidence from the Nigerian listed companies. Serbian Journal of Management, 9 (2), 263-280.

[40] Söderbom, M., Teal, F., \& Wambugu, A. (2002). Does firm size really affect earnings?

[41] Stock, G. N. \& Tatikonda, M. V. (2000). A Typology of Project-level Technology Transfer Processes. Journal of Operations Management, 26 (4): 719-737.

[42] Shuaibu, k., Ibrahim, A., \& Amin, I. M. (2019). Company Attributes and Firm Value of Listed Consumer Goods Companies in Nigeria. Journal of Research in Humanities and Social Science Volume 7 (5) 40-49.

[43] Tuanmat, T. Z., \& Smith, M. (2011). Changes in MAP in Malaysia. Asian Review of Accounting, 19 (3), 221-242.

[44] Watts, D., Yapa, P. W., \& Dellaportas, S. (2014). The Case of a Newly Implemented Modern Management Accounting system in a Multinational Manufacturing Companies. Australian Accounting Business and Finance Journal, 8 (2), $2-13$.

[45] Waweru, N. M. (2010). The origin and evolution of management accounting: a review of the theoretical framework. Problems and Perspectives in Management, 8 (3), $165,182$.

[46] Waweru, N., \& Uliana, E. (2008). Predicting change in management accounting systems: a contingent approach. Problems and Perspectives in Management, 6 (2), 72-84.

[47] Wie, T. K. (2003). The major channels of International Technology Transfer to Indonesia: An Assessment. Conference Sun Catch-Up Growth and Technology Transfer, University of Groningen, Groningen.

[48] Zehir, C., Muceildili, B., Akyuz, B., \& Celep, A. (2010). The Impact of Technology Investment on Firm Performance in National and Multinational Companies. Journal of Global Strategic Management, 1: 143-154. 